\title{
REPORT ON THE USE OF BIOFEEDBACK
}

\author{
Jeanette Mitchell B.Sc. (Physiotherapy), M.Sc.
}

'n Oorsig van die jongste liveratun oor bioterugrigting en veral terapeutiese aanwending, word gegee. Toestande wat geskik is vir behandeling, metodes van aanwending en seine word genoem. Verskeie studies word aangehaal maar geen gekontrolleerde studie bewys tot dusver statisties die waarde van bioterugrigting nie.

Biofeedback, or more accurately, electromyographic biofeedback, appears from the current literature to be a promising and relatively new electrotherapeutic modality. It is used mainly for the treatment of neuromuscular disorders. It is an adjunct to the more conventional methods of treatment and physiotherapists, with the co-operation of bioengineers, may use it increasingly in the rehabilitation of patients. However, as its use as such increases, new techniques as regards its pplication will need to be developed to suit the individual patient's needs.

Recent studies and reports of therapeutic successes have shown that electromyographic biofeedback, used with carefully directed instruction and motivation, enables a patient to obtain ". . . an extraordinary degree of voluntary control over physiological activities previously considered (to be) involuntary, reflexive or subconscious." (Nafpliotis, 1976), and this degree of control is obtained in a relatively short period of time.

Electromyographic biofeedback involves some auditory or visual representation of a patient's muscular activity, which the patient is taught to monitor in an attempt to alter muscular activity voluntarily to achieve a desired response. This procedure seems to work equally well in cases of flaccidity and spasticity (Inglis ef al., 1976). Apart from use in neuromuscular disorders, it has been extended to retraining correct muscular activity in chronic respiratory conditions (Johnston \& Lee, 1976), gait retraining in orthopaedic problems (Zimnicki \& Fernie, 1976), and in relaxation of muscle spasm in tension headaches (Budzynski et al., 1970) and torticollis (Brudny, Grynbaum \& Korein, 1974).

In applying the method of electromyographic biofeedback, a full functional assessment is made of the patient, who is then introduced to the apparatus. Surface electrodes, which are most often used, are applied to the skin after cleaning the area with alcohol and a conductive paste is used to ensure proper electrical contact. The types of visual and/or auditory stimuli to be expected, and which are desired to elicit a voluntary response, are explained to the patient before a few "trial runs" are conducted. Treatment sessions lasting 30 to 60 minutes are usually carried out two to three times a week, and continued until the patient shows some gain in voluntary control and/or functional improvement.

\section{Review of Current Literature}

The use of electromyographic biofeedback was first reported in 1960 as a method of neuromuscular reeducation in cases of hemiplegia (Marinacci \& Horande, 1960). Needle electrodes and auditory feedback were used, firstly on the unaffected limb in the initial training. The authors claimed a $20 \%$ improvement in the function of the affected limb within one hour of treatment. In 1964 Andrews reported a noticeable improvement in the motor unit activity in non-functioning muscles in cases of hemiplegia with paresis of from one to fourteen years duration. Needle electrodes and visual feedback were used. In similar cases of one year duration with tibialis anterior paresis, needle electrodes and both auditory and visual feedback were used and good results reported in 1973 by Johnson \& Garton. Some of these patients were reported to improve to the extent of no longer needing short-leg braces for footdrop control after one month's treatment.

Surface electrodes and visual feedback were used at the same time by Amato er al. (1973), to treat spasticity of the gastrocnemius muscle group of about nine years duration. They reported improvement after four months' training, which was manifested in some cases as a heel-strike to mid-stance pattern with the foot being held flat. Swaan ef al. (1974) extended the use of surface electrodes and auditory feedback to reduce muscle spasticity in cases of hemiplegia and, in the words of 
Inglis et al. (1976), (found the procedure to be generally) ". . . more effective than conventional rehabilitation methods."

Brudny et al. (1974) found that the improvement in the function of the hemiplegic hand even 12 months or longer after onset of the hemiplegia lasted from two to twelve weeks after treatment with surface electrodes and auditory and visual feedback. They used four arbitrary grades of improvement in their study and reported that prehension became possible in about onethird of their cases. Brudny et al. (1976) carried out a follow-up three months to three years after treatment of patients with a hemiparesis who had received electromyographic biofeedback training. They found that approximately half had made and retained a significant functional improvement.

It was not until 1975, however, that the first attempt at a scientifically controlled study was reported by Basmajian et al. Again surface electrodes and auditory and visual feedback were used on patients with foot-drop following CVA. In this study, the effects of electromyographic feedback used with conventional physiotherapy were compared with those of standard rehabilitation methods alone (control group), assessing changes in muscle strength, range of motion in involved joints, and gait patterns. They found that approximately twice as much improvement in muscle strength and range of motion was shown in the group receiving electromyographic biofeedback and physiotherapy treatment as in the control group.

In 1976, Takebe \& Basmajian also compared the gait of similar patients divided into three groups - those receiving biofeedback training, those receiving treatment with a peroneal nerve stimulator, and those receiving only intensive physiotherapeutic exercise. Generally speaking, they found the least improvement in the last group.

One of the latest reports on the use of electromyographic biofeedback is by Baker et al. in April 1977 They have applied this technique to patients with incomplete spinal cord lesions, paralysis from poliomyelitis, spasmodic torticollis and hemiplegia of 10 years duration, all of whom show ". . . promising results in terms of muscle re-education and functional improvement ..." (Baker et al., 1977).

Apart from its use in the above types of cases, electromyographic biofeedback has been reported to be used with success in teaching diaphragmatic breathing exercises (Black et al., 1969), and in retràining correct breathing patterns in emphysematous patients (Johnston \& Lee, 1976). Again surface electrodes and auditory and visual feedback were used.

Biofeedback has also been used with success as an aid in head-position training in the cerebral palsied child (Wooldridge \& Russel, 1976). Wooldridge et al., 1976 , also report the successful use of an extension of this procedure in gait-training in cerebral palsied children, where the objective was either improved knee flexion or extension. In this case, where biofeedback is used to retrain a more functional gait pattern, the technique has been simplified. Instead of using the electromyograph with needle or surface electrodes to enable feedback via auditory or visual stimuli, an electrogoniometer and auditory feedback unit are used. In other cases of gait retraining, as for example in prosthetic training in geriatric above-knee amputees (Zimnicki \& Fernie, 1976), an even simpler mechanism enabling biofeedback has been designed. This consists of an electrical switch fitted to the knee joint of the prosthesis, which is activated by the joint position, thereby triggering a buzzer - the auditory feedback mechanism. However, the principle of the procedure remains the same.
This review of the current literature indicates that although many different studies involving various conditions have been conducted, there are none reported to date which show a controlled scientific approach with statistics to give validity to the claims of improvement or therapeutic success made. Therefore, more controlled studies are obviously necessary in this field, and good experimental design and analysis are essential for an objective assessment of biofeedback, as a technique of value in rehabilitation, to be possible.

\section{References}

1. Amato, A., Hermsmeyer, C., Kleinman, K. (1973): Use of electromyographic feedback to increase inhibitory control of spastic muscles. Phys. Ther., 53, $1063-1066$

2. Andrews, J. (1964): Neuromuscular re-education of the hemiplegic with the aid of the electromyograph. Arch. Phys. Med. Rehabil.. 45, $530-532$.

3. Baker, M., Regenos, E., Wolf, S. L., Basmajian, J. V (1977): Developing strategies for biofeedback. Applif cations in neurologically handicapped patients. Phys. Ther., 57, $402-408$.

4. Barber, T. (ed.) (1971): Biofeedback and self-control. Chicago, Aldine-Atherton.

5. Basmajian, J., Kukulka, C., Narayan, M. G., Takebe, K. (1975): Biofeedback treatment of foot-drop after stroke compared with standard rehabilitation technique, Arch. Phys. Med. Rehabil., 56, $231-233$.

6. Black, J., Lagerson, J., Zohman, L. (1969): A feedback device for teaching diaphragmatic breathing. Am. Rev. Respir. Dis., 100, $335-348$.

7. Booker, H., Rubrow, R., Coleman, P. (1969): Simplified feedback in neuromuscular retraining: An automated approach using electromyographic signals. Arch. Phys. Med. Rehabil., 50, 621-625.

8. Brudny, J., Grynbaum, B., Korein, J. (1974): Spasmodic torticollis: Treatment by feedback display of EMG. Arch. Phys. Med. Rehabil., 55, $403-408$.

9. Brudny. J., Korein, J., Grynbaum. B., Friedman, L. W., Weinstein, S., Sachs-Frankel, G., Belandres, P. V. (1976): EMG feedback therapy; review of treatment of 114 patients. Arch. Phys. Med. Rehabil., 57, $55-61$

10. Brudny, J. Korein, J., Levidow, L., Grynbaum, B., Lieberman. M., Friedman, L. W. (1974): Sensory feedback therapy as a modality of treatment in CNS disorders of voluntary control. Neurology, 10 $925-932$.

11. Budzynski, T., Stoyva, J., Adler, C. (1970): Feedback-induced muscle relaxation: Application to tension headache. J. Behav. Ther. Exp. Psychiatr., 1, $205-211$.

12. Grynbaum, B., Brudny, J.. Korein, J., Belandres, P. V. (1976): Sensory feedback therapy for stroke patients. Geriatrics, 31, $43-47$

13. Harris, F. A., Spelman, F. A., Hymer, J. W. (1974): Electronic sensory aids for cerebral palsied children. Phys Ther., 54, 354 - 365.

14. Inglis, J., Campbell, D., Donald, M. W. (1976): Electromyographic biofeedback and neuromuscular rehabilitation. Canad. J. Behav. Sci.. 8, $299-323$.

15. Inglis, J., Sproule, M., Leicht, M, Donald, M. W. Campbell, D. (1976): Electromyographic biofeedback treatment of residual neuromuscular disabilities after cerebrovascular accident. Physio. Can. 28, $260-264$.

16. Johnson, H., Garton. W. (1973): Muscle re-education in hemiplegia by use of electromyographic device. Arch. Phys. Med. Rehabil., 54, $320-322$.

17. Johnston, R., Lee, Kyu-Ha (1976): Myofeedback. A new method of teaching breathing exercises in emphysematous patients. Phys. Ther., 56, 826-829. 
18. Karlins, M., Andrews, L. (1972): Biofeedback. Turning on the power of your mind. Philadelphia, J. B. Lippincott Co.

19. Kulkulka, C. G., Basmajian, J. V. (1975): Assessment of an audiovisual feedback device used in motor training. Amer. J. Phys. Med., 54, $194-208$.

20. Lee, Kyu-Ha., Hill, E., Johnston, R., Smiehorowski, Th. (1976): Myofeedback for muscle retraining in hemiplegic patients. Arch. Phys. Med. Rehabil., 57, $588-591$

21. Maher, K. R. (1972): Auditory feedback of muscle action potentials: potentials to spasticity and athetosis. Proceedings of Productivity and the Cerebral Palsied. Sydney, Aust. Spastic Centre of NSW.

22. Marinacci, A. A., Horande, M. (1960): Electromyogram in neuromuscular re-education. Bull. Los Angeles Neurol. Soc., 25, 57 - 71.

23. Nafpliotis, H. (1976): Electromyographic feedback to improve ankle dorsiflexion, wrist extension, and hand grasp. Phys. Ther., 56, 821 - 825 .

24. Russel, G., Wooldridge, C. P. (1975): Case study: correction of an habitual head tilt using biofeedback techniques. Physio. Can., 27, 181-184.

25. Segal, J. (1975): Biofeedback as a medical treatment. $J A M A$ 232, 179 - 180.

26. Swaan, D., Van Wieringen, P. C. W., Fokkema, S.
D. (1974): Auditory electromyographic feedback therapy to inhibit motor activity. Arch. Phys. Med. Rehabil., 55, 251 - 254.

27. Takebe, K., Basmajian, J. V. (1976): Gait analysis in stroke patients to assess treatments of foot-drop. Arch. Phys. Med. Rehabil., 57, 305-310.

28. Takebe, K., Kukulka, C. G., Narayan, M. G., Milner, M., Basmajian, J. V. (1975): Peroneal nerve stimulator in rehabilitation of hemiplegic patients. Arch. Phys. Med. Rehabil., 56, 237 - 240.

29. Wolf, S. L. (1976): Comments. Phys. Ther., 56, 830 831.

30. Wolpert, R., Wooldridge, C. P. (1975): The use of electrotherapy as biofeedback therapy in the management of cerebral palsy: a review and case study. Physio. Can., 27, 5 - 9.

31. Wooldridge, C. P., Leiper, C., Ogston, D. G. (1976): Biofeedback training of knee joint position of the cerebral palsied child. Physio. Can., 28, $138-143$.

32. Wooldridge, C. P., Russel, G. (1976): Head position training with the cerebral palsied child: an application of biofeedback techniques. Arch. Phys. Med. Rehabil., 57, 407 - 414.

33. Zimnicki, B., Fernie, G. R. (1976): Biofeedback and the lower extremity amputee: a new training aid. Physio: Can., 28, 79 - 82. 